PROPOSED CALIFORNIUM-252 USER FACILITY FOR NEUTRON SCIENCE

AT OAK RIDGE NATIONAL LABORATORY

$$
\text { CONF- } 961041--1
$$

R. C. Martin, R. R. Laxson, and J. B. Knauer

Chemical Technology Division

Oak Ridge National Laboratory*

P.O. Box 2008

Oak Ridge, TN 37831-6385
PECEVED

DCT 10 1989

OSTI

To be presented at the

3rd Topical Meeting on Industrial Radiation and Radioisotope Measurements and Applications

Raleigh, North Carolina

October 6-9, 1996

*Managed by Lockheed Martin Energy Research Corp., under contract DE-AC05-96OR22464 with the U.S. Department of Energy. 


\section{DISCLAIMER}

This report was prepared as an account of work sponsored by an agency of the United States Government. Neither the United States Government nor any agency thereof, nor any of their employees, makes any warranty, express or implied, or assumes any legal liability or responsibility for the accuracy, completeness, or usefulness of any information, apparatus, product, or process disclosed, or represents that its use would not infringe privately owned rights. Reference herein to any specific commercial product, process, or service by trade name, trademark, manufacturer, or otherwise does not necessarily constitute or imply its endorsement, recommendation, or favoring by the United States Government or any agency thereof. The views and opinions of authors expressed herein do not necessarily state or reflect those of the United States Government or any agency thereof. 


\title{
PROPOSED CALIFORNIUM-252 USER FACILITY FOR NEUTRON SCIENCE AT OAK RIDGE NATIONAL LABORATORY
}

\author{
R. C. Martin, ${ }^{1}$ R. R. Laxson, ${ }^{1}$ and J. B. Knauer ${ }^{1}$
}

The Radiochemical Engineering Development Center (REDC) at Oak Ridge National Laboratory has petitioned to establish a Californium-252 User Facility for Neutron Science for academic, industrial, and governmental researchers. The REDC Californium Facility (CF) stores the national inventory of sealed ${ }^{252} \mathrm{Cf}$ neutron sources for university and research loans. Within the $\mathrm{CF}$, the ${ }^{252} \mathrm{Cf}$ storage pool and two uncontaminated hot cells currently in service for the Californium Program will form the physical basis for the User Facility. Relevant applications include dosimetry and experiments for neutron tumor therapy; fast and thermal neutron activation analysis of materials; experimental configurations for prompt gamma neutron activation analysis; neutron shielding and material damage studies; and hardness testing of radiation detectors, cameras, and electronics. A formal User Facility simplifies working arrangements and agreements between U.S. Department of Energy facilities, academia, and commercial interests.

${ }^{1}$ Oak Ridge National Laboratory, Oak Ridge, TN 37831-6385, USA.

\section{Introduction}

The heavy element ${ }^{252} \mathrm{Cf}$ is an intense neutron emitter that is readily encapsulated in compact, portable neutron sources. Californium-252 is used in a variety of industrial and research applications 
such as elemental neutron activation analysis, neutron radiography, tumor therapy, reactor startup sources, and nuclear and waste assays (Osborne-Lee and Alexander, 1995). Californium-252 has a half-life of 2.645 years and decays by alpha emission (96.9\%) and spontaneous fission (3.1\%). One milligram of ${ }^{252} \mathrm{Cf}$ emits $2.314 \times 10^{9}$ neutrons/s, with average energy of $2.1 \mathrm{MeV}$. The Radiochemical Engineering Development Center (REDC) Californium Facility (CF) maintains the national inventory of sealed ${ }^{252} \mathrm{Cf}$ sources for university and research loans in its water-filled storage pool and processes the national supply of ${ }^{252} \mathrm{Cf}$ after production in the neighboring High Flux Isotope Reactor (HFIR). The CF represents a unique national resource that until now has only occasionally been used by outside researchers. The REDC at Oak Ridge National Laboratory (ORNL) has petitioned to establish the CF as a Californium User Facility for Neutron Science for academic, industrial, and governmental researchers. Designation of the $C F$ as a User Facility will make it more widely available and more visible to research and commercial interests outside the U.S. Department of Energy (DOE). A Californium User Facility can provide a cost-effective option for those who want to perform exploratory studies with ${ }^{252} \mathrm{Cf}$ sources without requiring the capital outlay or addressing the regulatory issues involved in source purchase or loan. The REDC would like to make these resources available to outside users to encourage research and expanded commercial applications of ${ }^{252} \mathrm{Cf}$.

Specific resources and areas in the $\mathrm{CF}$ to be made available to users include the walk-in, contamination-free hot cells designated as Cell B and Cell C; the ${ }^{252} \mathrm{Cf}$ storage pool, available neutron sources, and pneumatic transfer capabilities; and gamma spectroscopy equipment. Figure 1 is a floor plan of the CF showing the location of Cells B and C and the storage pool (location 8) and lists the capabilities in Cell C for $\mathrm{x}$-radiography, neutron assay, and helium leak testing of sealed capsules. Additional resources are available within the REDC such as in-house analytical chemistry support 
for alpha, beta, gamma, and neutron spectroscopy and other analytical and instrumental techniques. REDC has additional expertise in radioactive materials transportation and shielding, including computational capabilities.

\section{Experimental Scenarios}

Two experimental scenarios are currently available. Californium-252 sources can be made available to users in a walk-in-clean hot cell, or the irradiation sample or experiment can be pneumatically transferred to or physically lowered into the water-filled ${ }^{252} \mathrm{Cf}$ storage pool.

After hands-on setup of an experiment inside one of the hot cells, personnel are evacuated and the cell is closed. Sealed ${ }^{252} \mathrm{Cf}$ sources are then pneumatically transferred from the storage pool into the cell and positioned for the experiment using remote manipulators. Individual source strengths from $<1 \mu \mathrm{g}$ to tens of milligrams of ${ }^{252} \mathrm{Cf}$ can be made available. Total source strengths up to $50 \mathrm{mg}$ $\left(\sim 10^{11}\right.$ neutrons/s) can be transferred into Cell $\mathrm{C}$, and up to $3.7 \mathrm{mg}$ into Cell $\mathrm{B}$.

The other irradiation option is the ${ }^{252} \mathrm{Cf}$ storage pool, a large water tank containing the REDC inventory of sealed ${ }^{252} \mathrm{Cf}$ sources (Figure 2). An irradiation sample can be pneumatically transferred into the storage lattice and the neutron field tailored by rearranging the neighboring sources. Alternatively, larger samples and watertight experiments can be lowered into the thermalized underwater neutron field of the storage pool. The storage pool typically contains one hundred to several hundred milligrams of ${ }^{252} \mathrm{Cf}$. 


\section{Experiments at the Californium Facility}

The versatility of the $\mathrm{CF}$ for neutron science research is demonstrated by some previous experiments in the medical applications of neutrons, radiation damage experiments, and materials activation for gamma spectroscopy. A major advantage of irradiation testing at the $\mathrm{CF}$ is the accessibility and controlled experimental conditions and neutron fields compared with, for example, those of a reactor pool. Experimental setup in the walk-in hot cells is convenient, and real-time data acquisition is simpler than in a reactor experiment. As a rule of thumb, the fast neutron dose equivalent rate is approximately an order of magnitude greater than the gamma, so distinguishing between neutron and gamma effects is simpler than in the combined field of a reactor core. Although the CF cannot duplicate the high neutron fluxes found in the core of a reactor, experiments can be performed on samples much larger than would be possible in, for example, a hydraulic or pneumatic rabbit, and the encapsulated ${ }^{252} \mathrm{Cf}$ provides a convenient source of fast neutrons that is never subject to reactor downtime. Higher-flux requirements can be addressed by the neighboring HFIR User Facility at ORNL.

The REDC has an active collaboration with Wayne State University (WSU) regarding ${ }^{252} \mathrm{Cf}$ neutron brachytherapy (i.e., inserting the radioactive source directly into a tumor to kill the cancerous cells). The Gershenson Radiation Oncology Center of WSU, Detroit, Michigan, is the only medical center in the United States presently using ${ }^{252} \mathrm{Cf}$ to treat cancer patients. J. G. Wierzbicki of WSU previously performed dosimetric studies at the $\mathrm{CF}$ for an existing ${ }^{252} \mathrm{Cf}$ source configuration, and WSU and ORNL are currently collaborating with a manufacturer of remote afterloading equipment on the fabrication of miniature, high-strength ${ }^{252} \mathrm{Cf}$ sources for brachytherapy (Wierzbicki, 1996). 
Californium-252 can also be applied to boron neutron capture therapy studies, as demonstrated in a recent experiment by T. E. Byrne of the University of Tennessee, Knoxville. To test the effectiveness of several novel boron-containing compounds for killing tumor cells in a neutron field, Dr. Byrne irradiated test tubes containing living cells in a ${ }^{252} \mathrm{Cf}$ thermal neutron field of $2 \times 10^{8}$ neutrons $/ \mathrm{cm}^{2} / \mathrm{s}$ (Byrne, 1996). Figure 3 shows the experimental arrangement in Cell $\mathrm{C}$ of the CF.

To test the neutron survivability of an avalanche photodiode (APD) detector to be used in highenergy physics experiments at the CERN accelerator in Switzerland, a team from Northeastern University and the University of Minnesota assembled an experiment in Cell C with real-time data acquisition from the APD while undergoing irradiation by up to $28 \mathrm{mg}$ of ${ }^{252} \mathrm{Cf}$ (Reucroft, et al., 1996). In this experiment, the ${ }^{252} \mathrm{Cf}$ sources provided a good approximation of the expected APD inservice neutron flux.

Previous experiments at the $\mathrm{CF}$ include the neutron activation of a steel sample for elemental gamma analysis during an extended HFIR outage. The x-radiographic facilities in Cell $\mathrm{C}$ have been used for weld evaluation on request. Discussions for potential projects include the testing of detectors for neutron radiography, establishment of fast neutron and prompt neutron activation gamma spectroscopy capabilities, testing the survivability of cameras used for reactor and hot cell surveillance, cold neutron studies, and educational experiments for a University of Tennessee nuclear engineering course. 


\section{User Facility Organization at Oak Ridge National Laboratory}

ORNL currently has 11 state-of-the-art experimental science facilities that are officially designated as user facilities (U.S. Department of Energy, 1993). These research facilities are designed to serve ORNL staff scientists and engineers as well as outside researchers from universities, industries, and government laboratories. A centralized Office of Science and Technology Partnerships (OSTP) has been established to promote a user-friendly environment at ORNL to expedite collaboration and use of the user facilities. Collaboration has been enhanced by the

relaxation of patent regulations. For example, outside institutions may now retain the title to patented inventions developed during use of an ORNL user facility and may conduct proprietary research on a full cost-recovery basis.

\section{Accessing the Californium User Facility}

A potential user will be able to access the proposed Californium User Facility by submitting a proposal to the REDC. Acceptance of proposals depends on scientific merit, suitability of the User Facility for the proposed project, and appropriateness of the work to DOE objectives. After acceptance of the proposal, the specific operating procedures, time allotted for work, user fees (if any), and collaborative arrangements will be determined. The OSTP will execute a user agreement between the user institution and Lockheed Martin Energy Research Corporation, the managing contractor of ORNL. This agreement stipulates the terms and conditions (including disposition of intellectual property) for the interaction. User agreements may be either proprietary or nonproprietary in nature, depending on the circumstances. 
The $\mathrm{CF}$ is unclassified and is located in an uncleared access area adjacent to the HFIR complex. Visitors must be issued passes by ORNL. Facility staff will oversee all experimental arrangements in order to ensure that all activities are conducted within the requirements of the facility safety documentation. Facility staff are available to facilitate user access into the hot cell facilities, transfer and position ${ }^{252} \mathrm{Cf}$ sources for the experiments, and coordinate work with other REDC service groups as needed. For routine experiments, facility personnel typically provide hot cell access and source transfers as needed; the users set up their experiments with limited input from staff. Access to the hot cell areas is governed by existing operating procedures under the guidance of on-site Health Physics personnel. An REDC-specific access training program is in place to facilitate unescorted user access to the nonradiological and radiological areas of the CF.

Additional information on accessing the proposed user facility may be obtained by telephoning (423) $576-2280$ [ $\operatorname{fax}(423) 576-6312]$ or writing to the address below:

\author{
Californium User Facility \\ Radiochemical Engineering Development Center \\ Oak Ridge National Laboratory \\ P.O. Box 2008, Building 7930 \\ Oak Ridge, TN 37831-6385
}

The Californium-252 Newsletter, periodically issued by REDC, also provides information of current interest to ${ }^{252} \mathrm{Cf}$ users. Requests to be placed on the distribution list for this newsletter can be sent to the above address. 


\section{References}

Byrne, T. E. (1996), University of Tennessee, Knoxville, private communication.

Osborne-Lee, I. W. and Alexander, C. W. (1995), CALIFORNIUM-252: A Remarkable Versatile Radioisotope, ORNL/TM-12706, Oak Ridge National Laboratory, Oak Ridge, TN.

Reucroft, S., Rusack, R., Ruuska, D. and Swain, J. (1996), Neutron Irradiation of $A P D s$ Using ${ }^{252} C f$, NUB-3132, Northeastern University, Boston, MA.

United States Department of Energy (1993), Oak Ridge User Facilities, Oak Ridge, TN.

Wierzbicki, J. G. (1996), Californium - Isotope for 21st Century Radiotherapy. NATO Advanced Research Workshop, Detroit, MI, April 24-28, 1996. 


\section{Figure Captions}

Figure 1. Floor plan of the Californium Facility, including a list of experimental capabilities at workstation 6 of Cell C. The proposed Californium User Facility will encompass Cell B, Cell C, the storage pool, the associated pneumatic transfer lines, and the available ${ }^{252} \mathrm{Cf}$ sources.

Figure 2. The ${ }^{252} \mathrm{Cf}$ storage pool in the Californium Facility. The storage lattice which contains the sources is visible at the bottom of the pool.

Figure 3. Experimental configuration for testing effectiveness of boron compounds in killing cancer cells in a neutron field, for boron neutron capture therapy studies. 


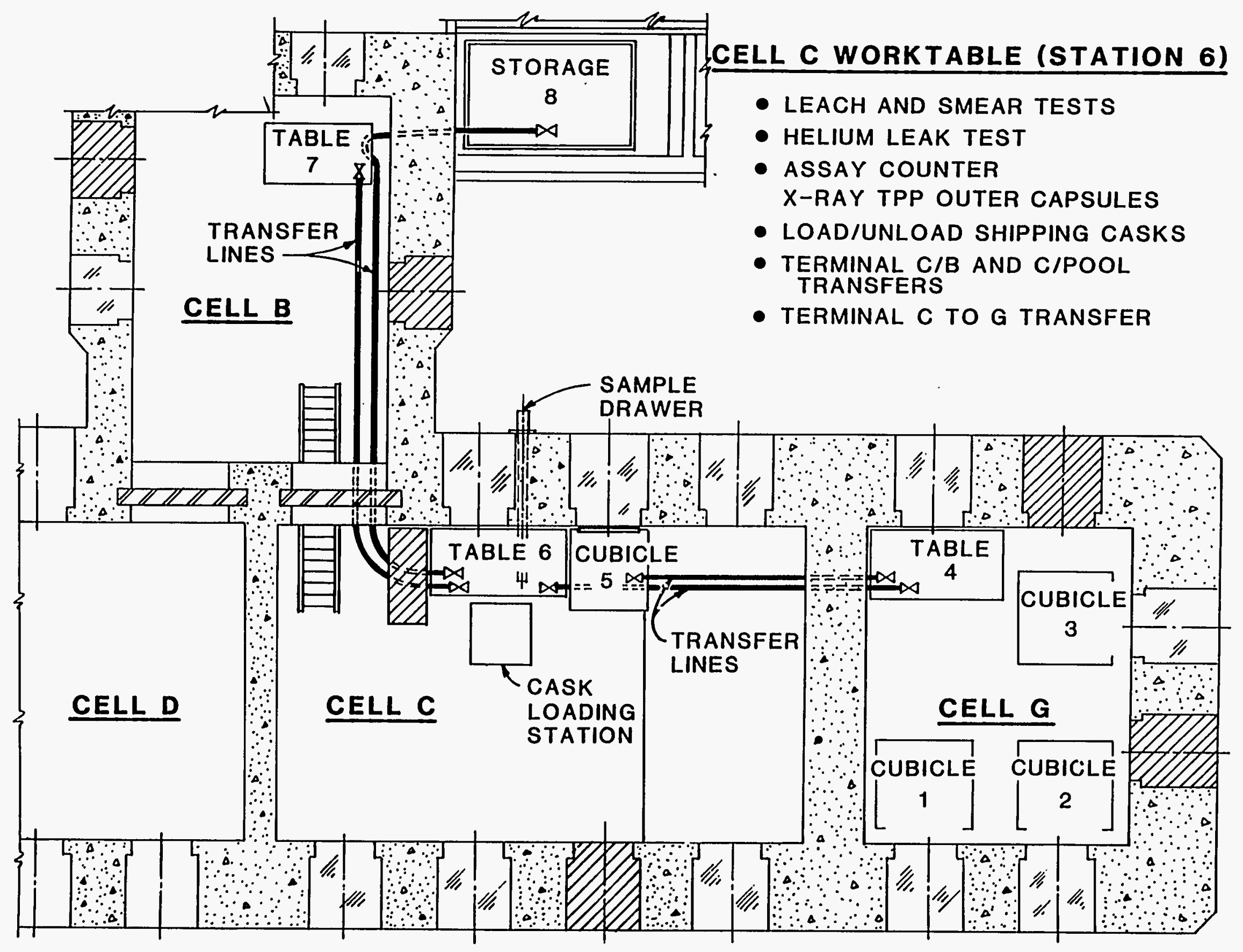




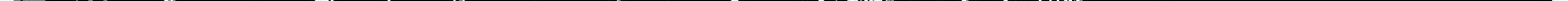




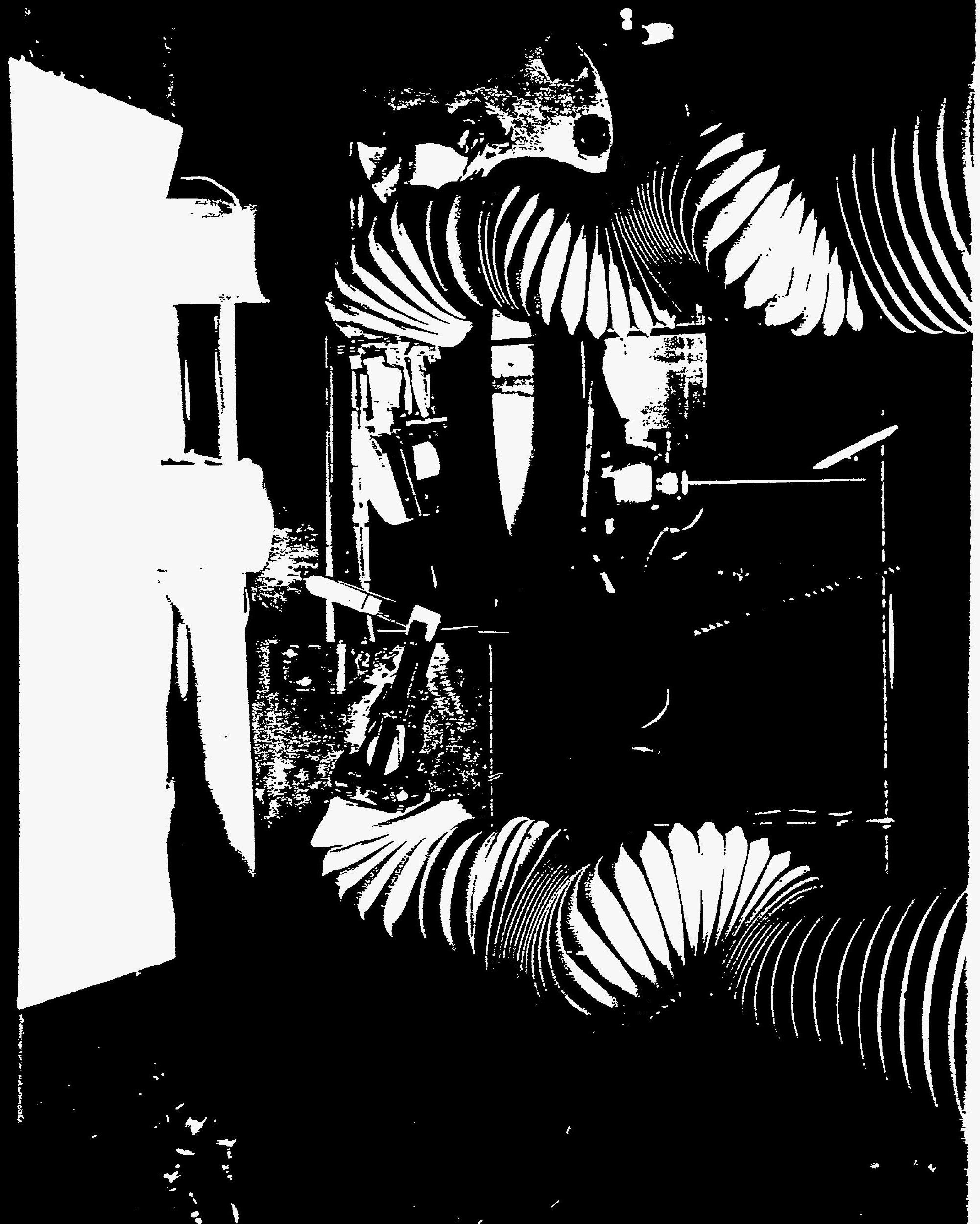




\section{DISCLAIMER}

Portions of this document may be illegible in electronic image products. Images are produced from the best available original document. 